\title{
Becker's nevus associated with basal cell carcinoma: an unusual presentation in a sun-protected area*
}

\author{
Priyadarshini Sahu ${ }^{1}$ \\ Sarabjit Kaur ${ }^{1}$
}

\author{
Surabhi Dayal ${ }^{1}$ \\ Vijay Kumar Jain ${ }^{1}$
}

Dear Editor,

Becker's nevus is a relatively common, hyperpigmented patch, frequently associated with hypertrichosis. ${ }^{1}$ Males are more commonly affected than females, with an incidence of around $0.25 \% .^{2}$ Becker's nevus may be associated with various cutaneous and skeletal anomalies. However, basal cell carcinoma (BCC) is a slow-growing; locally invasive tumour arising from pluripotent stem cells within the basal cell layer of the epidermis. ${ }^{2}$ It typically arises in areas of chronic sun exposure. Herein, the authors describe a sporadic case of Becker's nevus with isolated BCC over a sun-protected site in a young male aged 27 years, which has not previously been reported.

A 27-year-old male presented with a history of a single, widespread, brownish, flat lesion on the right upper chest. He had had the lesion for 15-16 years and it had remained unchanged throughout. The patient was not overtly concerned about the lesion. In addition, he complained of a well-defined, dark-coloured, elevated skin lesion over the brownish flat lesion. This dark-coloured, elevated lesion had emerged 3 months previously, increasing suddenly in size. During this period, the lesion's surface frequently exhibited erosions that bled spontaneously and then healed within a few days, only to recur again. There was no history of trauma, excessive sun exposure or previous inflammation in this area. The patient had been in his usual state of good health and his family history was inconsistent.

On physical examination, there was a brownish to hyperpigmented patch of $12 \times 10 \mathrm{~cm}^{2}$ in size, with irregular, well-defined margins located on the right upper chest extending from the right mid-clavicular line to the right mid-axillary line. It was associated with hypertrichosis, without any signs of photo-damage. Over the lateral aspect of this large, brownish, macular lesion, there was a hyperpigmented plaque, $3-4 \mathrm{~cm}$ in size, with a small crust in the centre of the lesion (Figure 1). Induration and tenderness manifested upon palpation. It also bled when touched and was not associated with any lymphadenopathy. Further examination and routine investigations revealed no associated cutaneous or systemic anomalies. However, dermoscopy could not be performed as no dermoscopes were available at the institution.

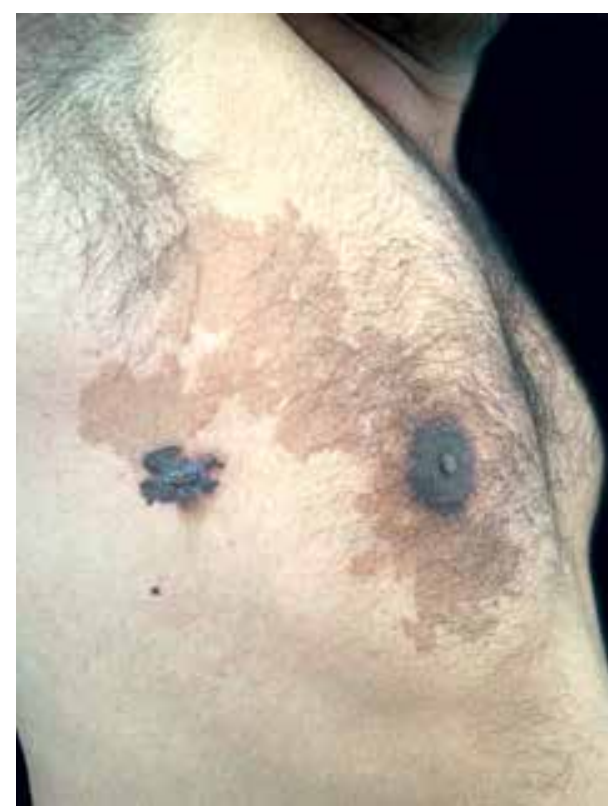

FigURE 1:

Hyperpigmented plaque of $3-4 \mathrm{~cm}$ in size, surmounted by a small crust at the centre of the lesion, localized at the lateral border of the brownish patch, located on the right upper chest

Received on 26.07.2015

Approved by the Advisory Board and accepted for publication on 25.10.2015

* Work performed at the Department of Dermatology, venereology and leprology, Pt B D Sharma Post Graduate Institute of Medical Sciences, Rohtak - Haryana, India.

Financial Support: None.

Conflict of Interest: None.

1 Pt B. D. Sharma Post Graduate Institute of Medical Sciences, Rohtak - Haryana, India. 
The entire hyperpigmented plaque was surgically removed with a small area of surrounding, brownish, macular lesion and sent for histopathology. The following differentials were kept: melanoma and BCC for the former lesion; Becker's nevus and café-au-lait macule for the latter. On histopathology, the brownish-coloured patch exhibited mild acanthosis of the epidermis and hypermelanosis of the basal layer, compatible with Becker's nevus. Moreover, the hyperpigmented plaque showed an aggregation of basaloid cells in a palisading arrangement in the superficial dermis, including melanin pigment both within and outside the tumour mass, which is characteristic of pigmented BCC (Figures 2 and 3). Thus, the final diagnosis was Becker's nevus with isolated pigmented BCC.

In addition to hypertrichosis and comedones, Becker's nevus may also be accompanied by various cutaneous and extra-cutaneous manifestations. Extra-cutaneous abnormalities associated with Becker's nevi are rare but include: breast hypoplasia, supernumerary nipples, aplasia of the pectoralis major muscle, ipsilateral limb shortening, segmental odontomaxillary dysplasia and lipoatrophy. Cutaneous involvement includes tinea versicolor, eczema, granuloma annulare, lymphangioma, generalized lichen planus and hypohidrosis. ${ }^{3}$

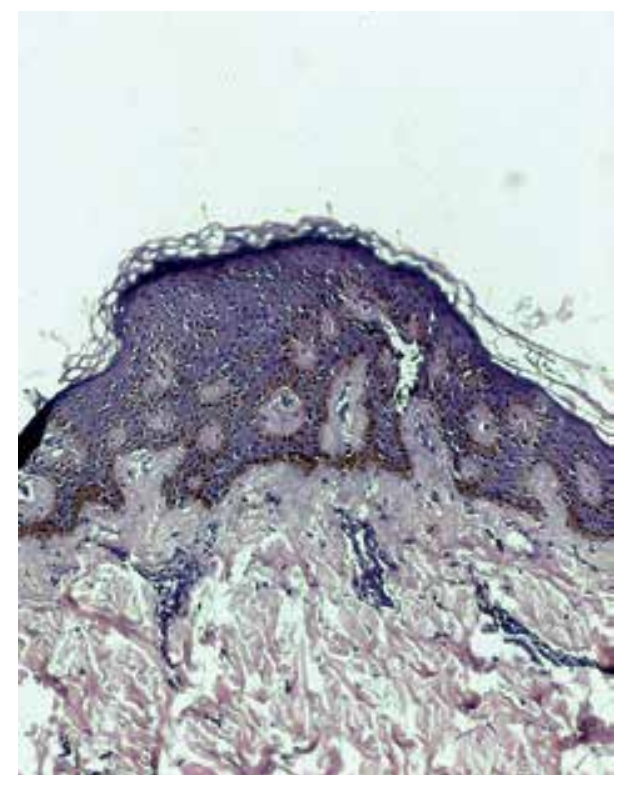

FIGURE 2: Histological examination showing hyperkeratosis with slight acanthosis, regular elongation of rete ridges and increased basal and suprabasal melanophages. (Hematoxylin \& eosin $x 10)$

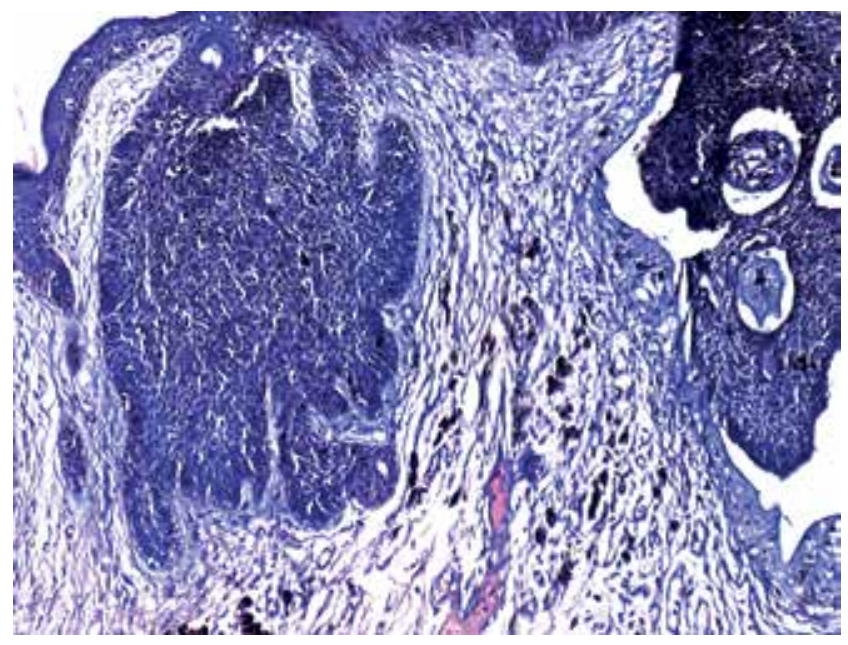

FIGURE 3: Histological examination revealing an aggregation in palisading arrangement of basaloid cells in the superficial dermis, including melanin pigment both within and outside the tumour mass. (Hematoxylin \& eosin $x 10)$

Basal cell carcinoma (BCC) is the most common non-melanoma skin cancer. ${ }^{4}$ The prevalence of this tumour increases within a population as exposure to sunlight increases. Thus, it is typically located in areas of chronic photo-damage, which undergo increased exposure to ultraviolet rays. ${ }^{2}$ However, in our patient, there was no sign of photo-damage and BCC occurred on the chest together with Becker's nevus, not a typical location for the malignancy. This was the most peculiar aspect of the case.

The literature only features one other case of $\mathrm{BCC}$ on the abdomen associated with Becker's nevus, concerning a 41-year-old Caucasian woman, described in 2007, and also associated with melanocytic nevus and smooth-muscle hamartoma. ${ }^{5}$ To the authors' knowledge, ours is the first case of isolated BCC associated with Becker's nevus on a 27-year-old male's right upper chest, an unusual location for BCC. Moreover, the area had not undergone photo-damage. The development of BCC in such a young patient is also an enigma. Thus, it can be assumed that Becker's nevus may represent a privileged site for the development of a non-melanocytic carcinoma like pigmented BCC. However, it could be a coincidental finding. Hence, further studies on the link between Becker's nevus and non-melanocytic carcinoma are required to substantiate the observation.] 


\section{REFERENCES}

1. Becker SW. Concurrent melanosis and hypertrichosis in the distribution of naevus unius lateris. Arch Derm Syphilol. 1949;60:155-60.

2. Moss C, Shahidullah H. Naevi and other Developmental Defects. In: Burns $T$ Breathnach S, Cox N, Griffiths C, editors. Rook's Textbook of Dermatology. 8th ed. Oxford: Wiley Blackwell; 2010. p.18.17-18.18.

3. Glinick SE, Alper JC, Bogaars H, Brown JA. Becker's melanosis. Associated abnormalities. J Am Acad Dermatol. 1983;9:509-14.

4. Miller DL, Weinstock MA. Nonmelanoma skin cancer in the United States: incidence. J Am Acad Dermatol. 1994;30:774-8.

5. Patrizi A, Medri M, Neri I, Fanti PA. Becker naevus associated with basal cell carcinoma, melanocytic naevus and smooth-muscle hamartoma. J Eur Acad Dermatol Venereol. 2007;21:130-2.

\author{
MAILING ADDRESS: \\ Dr Priyadarshini Sahu c/o Rabi Narayan Sahu \\ 432, sector IV \\ R.K.Puram, New Delhi. \\ E-mail-priyadarshini.sahu.9@gmail.com
}

How to cite this article: Sahu P, Dayal S, Kaur S, Jain VK. Becker's Nevus associated with basal cell carcinoma: an unusual presentation in a sun-protected area. An Bras Dermatol. 2017;92(1):145-7. 